\title{
1 Managing employees with dementia: a systematic review
}

2

3 Louise Thomson ${ }^{\mathrm{a}}$, Miriam Stanyon ${ }^{\mathrm{a}}$, Tom Dening ${ }^{\mathrm{a}}$, Richard Heron ${ }^{\mathrm{b}}$, Amanda Griffiths ${ }^{\mathrm{a}}$

4

$5 \quad{ }^{a}$ Division of Psychiatry and Applied Psychology, School of Medicine, University of Nottingham

$6 \quad$ bP International Ltd.

7

8

\section{Corresponding Author}

10 Louise Thomson

11 Division of Psychiatry and Applied Psychology, School of Medicine

12 University of Nottingham

13 Yang Fujia Building,

14 Jubilee Campus, Wollaton Road,

15 Nottingham, NG8 1BB

16 Telephone: 01157484314

17 Email: louise.thomson@nottingham.ac.uk

18

19

20 
Background: The experience of developing dementia while in employment has been explored from the point of view of the employee, but less is known about the perspectives, experiences and needs of employers.

Aims: To review systematically literature about the management of employees who develop dementia whilst in employment.

Methods: Databases searched included MEDLINE, EMBASE, PsycINFO, CINAHL, BNI, ABI Inform, ISI Web of Science, Open Grey and dementia journals database; 44 documents were identified for inclusion in the review: 22 journal papers, one $\mathrm{PhD}$ thesis and 21 articles, reports and webpages from the grey literature. As all documents were qualitative in nature a thematic synthesis of their content was undertaken.

Results: Three main themes and ten sub-themes were identified. The main themes concerned early presentation and identification in the workplace; reasonable adjustments for people with working age dementia; and the provision of information to raise awareness and facilitate informed choice. The evidence suggested that there is a lack of awareness about working age dementia and that this may impact negatively on employees. Guidance for employers offered suggestions for good practice.

Conclusions: Guidance for employers is increasingly available although it rarely refers to the evidence base. There is a need for future studies that explore the effectiveness of guidance and training initiatives for employers. Examples of good practice where employees with dementia have been well supported in the workplace and who have been able to leave the workforce with dignity, would be helpful.

Key words: working-age dementia; systematic review; employment practices; occupational health 
50 When dementia affects people between 30 and 65 years old, it is referred to as 'presenile', 'early onset' or 'working-age' dementia. Most individuals in this age group are likely still to be employed when symptoms first appear [1] and may experience difficulties at work due to mild cognitive impairment (MCI) for several years before formal diagnosis. In 2014 it was estimated that there were over 42,000 people with working-age dementia in the UK [2]. A review of worldwide studies suggested that the prevalence in the general population ranged from 0-700 per 100,000 [3]. Although the risk of dementia rises steeply with age, onset can occur in mid-life.

To date, there has been relatively little research on employment experiences of people with working age dementia, and no systematic reviews on this topic. Some research has focused on the work-related experience of people with dementia [4,5] and some on the social and economic consequences of their exit from the labour force $[6,7,8]$. These identify the difficulties experienced by people with workingage dementia. However, we also need to understand the perspectives, experiences and needs of employers. This article seeks to address this gap, by systematically reviewing the literature on the management of those who develop dementia whilst in employment.

In the UK, the Equality Act (2010) obliges employers to provide reasonable work adjustments for people living with conditions that qualify as a disability. Other jurisdictions have similar legislation, such as Australia (Disability Discrimination Act) and the USA (Americans with Disabilities Act). However, little is known about how these legal requirements are met with regard to dementia. The need for such knowledge will increase as more people work past the age of 65 [9]. This will help employers to put appropriate plans in place, and to minimise the reported difficulties experienced by employees with dementia and their families. Therefore, our aim was to conduct a systematic review of the published literature, scientific studies and other types of publication available on-line (the grey literature), to develop further our understanding of current research knowledge and employer practice in relation to the management of employees who develop working-age dementia. 
This systematic review followed guidance outlined by the Centre for Reviews and Dissemination [10]. Literature searches were conducted from September to October 2016. Ethics approval was not required as this was a systematic review.

All types of study design were included in the original search. These included both quantitative and qualitative study designs (such as those involving focus groups, interviews or non-participant observation). Participants were adults aged 18 and over who had a diagnosis of dementia or mild cognitive impairment. Studies were excluded if focussed on Parkinson's disease or other neurological disorders. Any reported occupational or employment-related outcome or topic was considered relevant. The focus was solely on the employment of the person with dementia; studies that focused on employment outcomes for carers were excluded. The studies could be performed in any country, but papers were restricted to the English language. There was no limitation on the time period of interest. Any reported work-related outcome or topic was considered relevant.

Literature search strategies were designed to identify all relevant studies regardless of publication status. Search strategies were developed for each database. Keywords for 'dementia', 'employment' and 'early onset' and 'policy' were the controlled terms and text words used in each database. The following were searched from inception to 1st July 2016: MEDLINE (Ovid); EMBASE (www.embase.com); PsycINFO; CINAHL; BNI; ABI Inform; ISI Web of Science; Open Grey (http://www.opengrey.eu/); Google Scholar; dementia journals database; and individual websites (see Appendix 1 for a complete list and search strategy).

[Figure 1 here]

The flow chart for the identification of documents is shown in Figure 1. Screening of titles was performed independently by two reviewers and non-relevant references and duplicates were discarded. In the second level of screening, abstracts of potentially relevant references were read. 
105

Those that did not meet the inclusion criteria were excluded. In cases of disagreement, the full article was obtained, independently inspected, and inclusion criteria applied by two reviewers. Disagreement was resolved through discussion and checked by a third reviewer where necessary. Justification for excluding articles from the review was recorded. In total, 69 documents from the scientific and grey literatures remained. Following data extraction including full screening of all 69 documents, a further 22 were excluded for not including relevant material and three excluded as duplicates. The remaining 44 studies and articles were of seven broad categories (see Table 1).

[Table 1 here]

For quality assessment of papers, the identification of criteria that are relevant to the specific review is advocated. As the journal papers identified in this review were all qualitative, we used the Critical Appraisal Skills Programme (CASP) tool. This tool was used to conduct quality assessments of articles describing the collection of primary research data; quality assessment scores are presented in Table 2.

[Table 2 here]

To enable qualitative synthesis, all articles were analysed using thematic analysis $[11,12]$ in order to integrate their content. This involved open coding to develop 'descriptive' themes. The constant comparison method was used to develop the themes which are further interpreted to yield 'analytical' themes.

\section{Results}

Three over-arching themes and ten sub-themes were identified (Table 3) and are described below. [Table 3 here] 
The first over-arching theme related to the early presentation and identification of dementia in the workplace. The literature highlighted the likelihood that a substantial number of people working are unaware of their developing condition. This was thought to be partly due to that fact that delays in diagnosis are particularly common for people with working age dementia [13]. Four sub-themes were identified: hiding difficulties; early symptoms; from symptoms to diagnosis; interactions with employees

The first sub-theme was 'Hiding Difficulties'. Many articles described how employees may often conceal their symptoms [4]. They may try to 'restrict' their activities when they experience new difficulties [14] or may not acknowledge difficulties as they go through a period of denial. It was noted that an employer (as a party other than an employee's partner or family member) can play a key role in persuading a person with suspected dementia to seek specialist advice [15].

Employees are likely to self-manage their symptoms as a first response rather than discuss concerns with their employers [4]. This can contribute to delays in diagnosis and can lead to pressure to improve on faltering performance at work [1]. In turn, this may lead to dismissal where performance fails to improve [16].

Even when diagnosed, employees may wish to conceal their diagnosis. Many fear the reactions of colleagues and employers, that they might not be able to continue working, that they would be bullied, or be discriminated against if looking for a new job $[13,17,18]$. However, there were also reports of colleagues 'rallying round' employees when they learn about their diagnosis [19].

The second sub-theme was 'Early Symptoms'. The articles described how symptoms of working age dementia are more varied than those typically observed in dementia later in life. Less common forms of dementia, such as frontotemporal dementia, are more frequent in those with working age dementia than in older groups. And although in this type of dementia, memory loss is common, other presentations such as changes in personality and behaviour can be involved [1,20]. These may be 
associated with, for example, to alcohol abuse, gambling or domestic conflict. These more varied presentations can also contribute to delays in obtaining a correct diagnosis.

Some of the symptoms most likely to be noted by employers are memory-related: such as difficulty remembering names $[4,14,21,22,23]$ and missing appointments [20,21,24]. Employees are noted as compensating for such forgetfulness via strategies such as keeping lists, calendars and clocks in front of them at work [22] or spending increasing time planning and organising their tasks [4].

Changes in various cognitive skills are commonly reported, such as disturbance in language [22], constant repetition during conversations [20,23], and reduced numerical ability [23]. Difficulties in managing cash and doing accounts have been reported. Other cognitive impairments include difficulties using logic or judgement and dealing with the abstract [22].

Psychological symptoms are frequently manifested. Depression is common, as are associated behaviours and emotions such as reluctance to engage with others, increased agitation, irritability or apathy [22]. Anxiety is also common [23]. Some employees initially attribute such symptoms to work-related stress [25]. Other psychological symptoms include delusions and hallucinations [26].

In one study of people with working age dementia, aggressive behaviour was reported in $50 \%$ of participants [23]. Most of this behaviour was verbal aggression, but some employees became physically aggressive. Some risk losing their jobs due to 'unacceptable behaviour' [23].

The decline in ability to perform to previous standards is one of the signs of working age dementia [20,23]. This can include: difficulty adjusting to new tasks [4], deficits in dexterity for complex tasks [22], multiple physical health complaints, increased absence from work [21,22] and a change in attitude to performance, for example changing from being a perfectionist to having a "that'll do" attitude [25]. Unexplained reductions in performance and the inability to make improvements demanded by employers often lead to dismissal for people who have yet to be diagnosed [16]. 
In the grey literature, the Australian Government's Job Access website [27] noted the following list of symptoms that may become apparent at work: forgetting appointments or meetings, confusion about time and place (e.g. forgetting the day of the week or being unable to identify where they are), difficulty finding the right words, difficulty concentrating, poor or decreased judgment (e.g. misjudging distance when driving), misplacing things, changes in personality or behaviour (rapid mood swings, or becoming confused and withdrawn), uncertainty about making important decisions, and losing confidence.

The third sub-theme was 'From symptoms to diagnosis'. The literature described how once symptoms are acknowledged, the confirmation of a diagnosis of dementia can be a long and difficult process. The average person diagnosed with working-age dementia has been in their current job for at least nine years [28]. It frequently takes more than a year to reach diagnosis [14]. Low diagnosis rates are partly due to the condition being relatively uncommon in people under 65 and partly due to symptoms being mistakenly attributed to other conditions such as stress or depression [13]. Undergoing investigations for dementia can itself be a stressful experience, and can be exacerbated where an employer fails to deal with the situation appropriately [28].

Diagnosis of working age dementia is challenging [14], largely due to the need to exclude other aetiologies. Referral to specialist units, such as memory clinics [29,30], is usually required for a correct diagnosis. Healthcare professionals often administer a range of physical (blood tests and neuroimaging) and psychological tests in the assessment of possible dementia that are not suitable for routine use in the workplace $[4,22,25,26,31,32]$.

Despite their fears beforehand, individuals with working age dementia do not report regretting having knowledge of their diagnosis. They often find that diagnosis helps them make sense of their experiences and make plans about how long they want to carry on working and explore what support their employers can provide [13]. Early identification can also allow time for handover of knowledge and responsibilities to colleagues and successors [33]. 
217 The fourth sub-theme was 'Interactions with Employees'. Advice on how employers should approach

218 and interact with an employee whom they know, or suspect, to have working-age dementia, was

219 offered in a number of articles. It included: sensitively asking employees if they have noticed they are

220 having memory or planning problems [20,33]; asking whether they have been having similar

221 problems at home, and whether these could be discussed with family members [33]; urging employees to get a medical evaluation from a specialist in memory loss [33].A careful approach, expressing concern for the individual employee, is recommended [20], as this can help minimise negative consequences triggered by a diagnosis such as anxiety, depression and suicidal ideation [25]. Participants in one study reported that their employers lacked empathy [30]. Experiences of traumatic cessation of employment and harsh treatment by employers were reported in several studies $[4,16,30]$.

In 2015 the UK's Alzheimer's Society published guidelines for supporting employees in the early stages of dementia [21]. They describe six workplace scenarios and suggest ways to respond in each, emphasising the importance of good communication throughout. This may include checking relevant policies and seeking advice from Human Resource (HR) or Occupational Health $(\mathrm{OH})$ professionals. An open and honest dialogue is encouraged, and one where the employee is given an overriding message of support, recognising that timing and extent of disclosure is ultimately the employee's decision. Notes of discussions and plans should be maintained.

The Dementia Engagement and Empowerment Project (DEEP) [34] is an initiative that seeks to bring together people with dementia in the UK with the aim of affecting change in services and policy. Their website also provides advice for employers, recommending that they have clear policies about how they can provide support. Where employees have a diagnosis of dementia, DEEP recommends that employers should outline to employees the support that is available, encourage employees to be aware of their symptoms and how they might affect them at work and explain the procedures that need to be followed. They also note that employers need to be flexible and compassionate about employees' needs to attend medical appointments [34]. 
246 The second over-arching theme identified from the literature related to the reasonable adjustments that

247 allowed people with dementia to remain in work for some period of time. Within this theme four subthemes were identified: the desire to stay in work; typical adjustments; the process of making adjustments; reported experiences of reasonable adjustments.

The sub-theme on the desire of people with working age dementia to stay in work was reflected in several journal articles, as was the importance for employers to facilitate this. People with working age dementia described the importance of remaining independent, using their skills and abilities and maintaining meaning and purpose through working life $[16,18,30]$. When people with working age dementia were asked about their needs, their overwhelming desire was for purposeful activity and the opportunity to remain in employment for as long as possible [16]. One study highlighted the shock associated with the prospective loss of employment for these employees and the future they had predicted for themselves [19].

Many studies explored the impact of job loss. There can be emotional and psychological consequences to giving up work or being forced to retire [35] such as devastating impacts on selfesteem and self-worth [26]. All participants with working age dementia in one study reported that leaving work had affected their families and their relationships, and for some that it caused financial hardship [4]. This highlights the important role of employers in enabling employees to remain in work for as long as both parties find possible and desirable.

A second sub-theme described the typical adjustments made for someone with dementia in the workplace. Establishing structure and routine is important [35] and can be supported by calendars, lists, diaries and keeping such items in a consistent location. Using smart devices to provide timely reminders of meetings, tasks and deadlines can help [36]. The introduction of disability leave, working from home, flexible working or redeployment to a new role has also been suggested [21]. 
273 Health and safety is a primary concern for employers. Guidance advises that it should be a priority to 274 determine whether the condition presents such problems for employees themselves or others $275[20,33,37]$, and where health and safety risks are high, adjustments should seek to reduce those risks 276 for the employee with dementia and/or other staff [21].

277

278 Co-workers may also need to be involved in accommodating colleagues with working age dementia 279 [33]; for example, when making adjustments to work schedules or arranging meetings for times when such employees are likely to be at their best [20].

281

Campaigning organisations and charities encourage employees to ask their employers for workplace adjustments $[38,39]$. Table 4 summarises the advice on reasonable adjustments described by UK's Alzheimer's Society [37,40], Australian Government Job Access website [27] and Alzheimer's Australia [39].

[Table 4 here]

The process of making adjustments was identified as a third sub-theme relating to reasonable adjustments. It is reported that a sense of control and autonomy is important for a person with working age dementia [25] and that it is helpful if the process of making adjustments is a collaborative one, involving both employer and employee [4,20,25,33]. Open discussion may help to prevent changes in job role from feeling punitive [4].

It is acknowledged that general guidelines about how to manage the work situation of a younger person with dementia are difficult to develop and therefore a case-by-case approach, based on consensus between key stakeholders and the employee should be adopted [23,41]. Young Dementia UK [42] note that the involvement (with the employee's consent) of the employee's GP or consultant 
can help employers assess specific difficulties and to decide on tasks employees can continue to do, tasks they may need to approach differently, and tasks that they may need to relinquish. The potential for helpful advice from occupational therapists and psychologists was also highlighted: for example, in assessing other (non-task specific) demands in the workplace and the impact on other aspects of the employee's mental health. The importance of regular review is noted [21].

In the UK, the Alzheimer's Society [17] encouraged employers to adopt good employment practices that support people with dementia to continue to work after a diagnosis. DEEP [34] also highlights the processes and practices that employers should adopt when making adjustment. These are summarised in Table 5.

\section{[Table 5 here]}

The final sub-theme related to reasonable adjustments concerned the reported experiences of those with working age dementia. The research studies reported that many people with working age dementia have experiences that are far from what is advised in the guidance described above. In cases reported by Chaplin \& Davidson [4], none of the participants said that they were offered any reasonable adjustments to their work role after diagnosis. They also reported a lack of consultation and felt that there was no real will in the workplace to find a more suitable job or acknowledge their remaining skills. Similarly, in another study with people with working age dementia, little assistance was available to help them keep working if they so wished [23]. In this study of 61 people, all but one had to give up their jobs as they were unable to fulfil their work commitments. This was for a variety of reasons including the inability to retain work-related insurance post-diagnosis, being laid off from more informal work contracts, as well as voluntary decisions to leave work to spend more time with family. Respondents in another study reported a sense of lack of agency, feeling conspired against and often being dismissed without consultation [30]. In cases where a diagnosis had yet to be made, it was common for an employee to lose their job due to poor performance before an opportunity for workplace adjustments was considered [15]. Some employees with working age dementia reported 
making self-directed adaptations to manage their condition [24]. These included developing new strategies to perform tasks. These strategies were reported as helpful in work but also for non-workrelated activities and hobbies.

The authors of one study suggest that employees working in lower paid/manual jobs are more likely to experience an 'all or nothing' approach from their employers, and face quicker dismissal. In contrast, those working in higher paid/non-manual and professional jobs are more likely to have more control over their daily tasks and more consideration may be given to retaining their unique knowledge and remaining skills [4].

The third and final over-arching theme identified from the literature related to the provision of information about working age dementia. Within this theme two sub-themes were identified: raising awareness; facilitating informed choices.

The first sub-theme concerned the importance of accurate information about working age dementia in raising awareness in the workplace. A lack of awareness of working age dementia in the general population and in the workplace was commonly reported in the literature we reviewed $[4,25]$. This was thought to result in lack of understanding and fear about how to interact with a person with dementia [18]. People with working age dementia revealed, for example, that co-workers often did not understand why they made mistakes [4].

Several articles noted the need to raise workplace awareness of possible signs and symptoms of dementia, to provide information about dementia in staff newsletters and noticeboards areas, and to provide training, perhaps by health and safety programmes $[1,13,24,34,41,43]$. Specific training for co-workers was highlighted as a way of ensuring that those who work closely with a person with dementia are patient, and that they listen and wait for their colleague with dementia to find the right 
words [23]. The need to tackle stigma, encourage open dialogue and create an environment where employees can talk about dementia was also highlighted [13].

Knowledge of employment law was also identified as a training need for health professionals working in services for people with dementia [4]. Improved awareness of working age dementia among general health professionals, particularly GPs, could encourage better multidisciplinary assessment and quicker referral to specialists [23].

The second sub-theme identified the need for information to facilitate informed decision making by people with working age dementia. The need for useful and timely information relating to working age dementia was highlighted in many of the studies and reports. It was also noted that information, support and services were difficult to access $[1,18,43]$. It was suggested that employers could be an important focal point for dissemination. DEEP, for example, recommend that employers should ensure that employees with working age dementia know to whom to turn for support, both inside and outside the organisation [34].

Individuals diagnosed with working age dementia reported that they struggled to understand state disability benefits and were unsure, for example, whether or not to remain in employment [43]. Financially-focused, informational support, including information about various state benefits, was noted as essential for those working at the time of diagnosis [25,26,37,38,44]. Lack of suitable information can make choosing between early retirement, redundancy or state benefits difficult and inappropriate choices may cause additional financial hardship [1,4,28,30,35]. Also noted was that as affected employees lose or leave their jobs, caregivers may also leave work in order to care for them, resulting in further loss of income [24]. Employers should be encouraged to recognize dementia as a reason for early retirement so as to maintain pension rights and other benefits $[31,45]$.

DEEP emphasise the importance of employers supporting people to retire gradually by such measures as: reducing hours and signposting to dementia friendly retirement clubs and activities [34]. As 
working age dementia progresses, it is highly likely that there will come a time when an employee is no longer able to fulfil a role within the organisation. At this stage, the literature makes clear that there needs to be an open and honest discussion about available options, including advice about pensions and benefits [13,20]. The UK's Alzheimer's Society [21] advises on the importance of reaching agreement about a dignified exit package and strategy with each employee.

\section{Discussion}

This systematic review has identified and described current knowledge in relation to the management of people who develop dementia whilst still in employment. The review identified 44 documents. Their main themes concerned early presentation and identification in the workplace; reasonable adjustments; and the provision of information both to raise awareness and allow employees with working age dementia to make informed choices. The main limitation of the review is that there may well be knowledge in working communities that has not been published. Since the topic of employment and dementia sits across a wide span of health, social and occupational domains it is possible that some omissions have been made. The aim of our review was to understand the perspectives, experiences, and needs of employers rather than the work-related experience of people with dementia; the latter has been the focus of previous research [4,5]. However, the literature concerning how to manage people with working-age dementia remained heavily reliant on both the perspectives and experiences of employees, and on best practice and advisory guides published by charities and interest groups. There is very little primary research examining $\mathrm{HR}$ or $\mathrm{OH}$ practices and interventions, or exploring the experiences of managers. Nevertheless, the experience of employees with working-age dementia is clearly relevant and provides important insights into the management practices they commonly experience, much of which they reported as negative.

The literature emphasised that early identification of dementia is important both for employer and employee both to minimise problems arising at work and to enable employees to continue to work after diagnosis should they so wish. Early identification can also help mitigate health and safety risks and allow time for handover of knowledge and responsibilities. Early identification in the workplace 
411 is challenging as employees conceal symptoms or self-manage them to reduce their impact at work.

412 Early symptoms can be varied and are manifested at work in a variety of ways: difficulty

413 remembering names, missing appointments, repetition during conversations, reduced numerical

414 ability, difficulty using logic, unexplained reductions in performance, increased agitation and

415 irritability, and symptoms of depression and anxiety. Employers are advised to interact sensitively

416 with employees suspected of having working-age dementia, expressing concern whilst supporting

417 them to access medical evaluations.

419 Although there is little evidence on the effectiveness of workplace adjustments for people with working-age dementia, studies reporting employees' experiences highlight their desire to stay in work and explain how employers can be supportive in this respect. A number of campaigning organisations and charities provide guidelines on type of adjustments that can be put in place and the importance of a collaborative approach to their implementation. However, as indicated above, the reported experiences of people with working age dementia appear to be far from what is advised in such guidance.

Information to raise awareness of the symptoms of working age dementia and to tackle stigma around the condition was highlighted as a need, enabling employees to acknowledge and discuss the problems they face managing people with dementia. Employers can help employees to talk about their diagnosis and difficulties by creating an environment where dementia can be discussed, where information about signs and symptoms is available, and where information about whom to turn to for support and advice is provided [21,30].

It was noteworthy that the papers reviewed did not fully explore the issue of employee consent and the ramifications of disclosure. While early disclosure may be desirable in order to facilitate reasonable adjustments, without appropriate advice and knowledge of the legal requirement for adjustments it may also, according to the literature, be associated with early exit from employment. 
439 The majority of advice to employers on management of the condition in the workplace appears to

440 have been delivered by clinicians via the employee. The need for its practical application in

441 workplace settings and the role of the $\mathrm{OH}$ professional in achieving mutually satisfactory outcomes

442 was either under-recognised or not explored.

444 The UK workforce is ageing, such that by $2020,1: 3$ British workers will be over 50 years of age 445 [46,47]. It is likely that employers will need to retain older workers to access scarce skills. At the 446 same time, the incidence of dementia also increases with age, doubling every 5 years from the age of 44765 to 90 [48]. Many with an early diagnosis will be capable of sustained, productive employment with reasonable adjustments. The literature does not examine the business case for managing dementia to retain critical skills.

450

Neither did the literature we reviewed explore whether employers should include cognitive testing as part of employee review procedures, or whether employers and $\mathrm{OH}$ professionals should take a more proactive approach towards detecting and diagnosing cognitive impairment amongst employees. This will be the subject for further research from our group.

The 'Dementia Friends' initiative run by the Alzheimer's Society in the UK aims to make positive changes to the way employers and businesses respond to dementia in the community [28]. Information sessions for businesses help all their employees learn about dementia and the steps they can take to help. Many organisations have committed to helping their employees understand more about dementia through this initiative.

In conclusion, there is an acknowledged lack of awareness among employers about working age dementia, and how it may be better managed for the benefit of employees and employers. Guidance for employers is increasingly becoming available although it rarely refers to the evidence base. There is a need for studies that explore the effectiveness of guidance for both employees and employers, as well as the value of awareness raising and training initiatives. Examples of good practice where 
employees with dementia have been able to remain in the workforce for as long as is practicable and

468 who have left the workforce with dignity and support, would be helpful.

469

470 Key points:

471 - Early identification of dementia is important both for employer and employee to minimise 472 problems arising at work and enable employees to continue to work after diagnosis should they so wish

474

- $\quad$ People with working age dementia often have a strong desire to stay in work for as long as possible, and this can be facilitated by reasonable adjustments that are regularly reviewed.

- Employers can help employees to talk about their diagnosis and difficulties by creating an environment where dementia can be discussed, and where information is available about signs and symptoms, and whom to turn to for support and advice

479

480

\section{Acknowledgements}

481

The authors acknowledge the support of Public Health England. They would also like to acknowledge

Laura Dunk and Laurie Hare Duke who contributed to the early stages of this review, and Emma

Young and Samantha Roberts the Information Specialists who planned and conducted the literature searches.

485

486

\section{Competing interests}

487

No potential competing interests was reported by the authors.

Funding

490 This work was supported by a grant from Public Health England, UK. 
1. Thompson D. Service and Support Requirements for People with Younger Onset Dementia and their Families. Sydney: Social Policy Research Centre, University of New South Wales. 2011.

2. Prince M, Knapp M, Guerchet M, McCrone P, Prina M, Comas-Herrera A, et al. Dementia UK: Overview 2014.2 Available from: http://eprints.1se.ac.uk/59437/1/Dementia UK Second edition - Overview.pdf.

3. Vieira RT, Caixeta L, Machado S, Silva AC, Nardi AE, Arias-Carrión O, et al. Epidemiology of

4. Chaplin R, Davidson I. What are the experiences of people with dementia in employment? Dementia 2016;15:147-161.

5. Ohman O, Nygard L, Borell L. The vocational situation in cases of memory deficits or young onset dementia. Scandinavian Journal of Caring Sciences. 2001;15:34-43.

6. Harris PB, Keady J. Selfhood in younger onset dementia: Transitions and testimonies. Aging and Mental Health. 2009;13:437-444.

7. Luscombe G, Brodaty H, Freeth S. Younger people with dementia: diagnostic issues, effects on

10. Centre for Reviews and Dissemination. Systematic reviews: CRD's guidance for undertaking reviews in health care [internet]. 2009. York: University of York, Centre for Reviews \& Dissemination. Available from: https://www.york.ac.uk/media/crd/Systematic_Reviews.pdf.11. Barnett-Page E, Thomas J. Methods for the synthesis of qualitative research: a critical review.

8. Roach P, Keady J. Younger people with dementia: time for fair play. British Journal of Nursing

9. Bloom DE, Boersch-Supan A, Mcgee P, Seike A. Population aging: facts, challenges, and 2008;17(11):690-690. ESRC National Centre for Research Methods. NCRM Working Paper Series, Methods for the synthesis of qualitative research: a critical review [internet]. 2009. Available from: http://eprints.ncrm.ac.uk/690/1/0109\%2520Qualitative\%2520synthesis\%2520methods\%2520pa per\%2520NCRM.pdf

12. Thomas J, Harden A. Methods for the thematic synthesis of qualitative research in systematic reviews. BMC Medical Research Methodology 2008;8:45.

13. McNamara G. Supporting people with dementia in the workplace [internet]. 2014. Available from: https://www.personneltoday.com/hr/supporting-people-dementia-workplace/.

14. Keady J, Nolan M. Younger onset dementia: developing a longitudinal model as the basis for a research agenda and as a guide to interventions with sufferers and carers. Journal of Advanced Nursing 1994;19:659-669. 

MJFJ, et al. Caregivers' perspectives on the pre-diagnostic period in early onset dementia: A long and winding road. International Psychogeriatrics 2011;23:1393-1404.

16. Chaston D. Younger adults with dementia: a strategy to promote awareness and transform perceptions. Contemporary Nurse. 2010;34:221-229.

17. Alzheimer's Society. Employment and dementia [website]. UK. Available from: http://www.alzheimers.org.uk/site/scripts/documents info.php?documentID=1836. 2014

18. Pipon-Young FE, Lee KM, Jones F, Guss R. I'm not all gone, I can still speak: the experiences of younger people with dementia. An action research study. Dementia 2012;11:597-616.

19. Clemerson G, Walsh S, Isaac C. Towards living well with young onset dementia: An exploration of coping from the perspective of those diagnosed. Dementia 2014;13:451-466.

20. Fleck C. A lot to lose. HR Magazine, 2015;9:41-45.

21. Alzheimer's Society. Creating a dementia friendly workplace: A practical guide for employers. London: Alzheimer's Society. 2015.

22. Dodson J. Recognizing early senility. Occupational Health Nursing. 1985;33:199-201.

23. Haase T. Early-onset dementia the needs of younger people with dementia in Ireland [internet]. 2005. Available from: http://www.lenus.ie/hse/handle/10147/196453.

24. Wahab EO, Ikebudu CJ. Quality of life of patients with early onset dementia in Nigeria. International Letters of Social and Humanistic Sciences. 2014;28-42.

25. Mitchell H. Coping with young onset dementia: Perspectives of couples and professionals [dissertation]. Cardiff: Cardiff University; 2012.

26. Werner P, Stein-Shvachman I, Korczyn AD. Early onset dementia: clinical and social aspects. International Psychogeriatrics 2009;21:631-636.

27. Job Access. Alzheimer's disease: A brief summary of Alzheimer's disease with tips on making adjustments in the workplace [internet]. 2016. Available from: http://jobaccess.gov.au/content/alzheimers-disease. 2016

28. Public Health England. New dementia campaign launches as research reveals the true cost to business of dementia. 2014.

28. Brechin D. Dementia in the workforce. Science and Public Affairs 2004; 6-7

29. Bakker C, De Vugt ME, Vernooij-Dassen M, Van Vliet D, Verhey FR, Koopmans RT. Needs in early onset dementia: a qualitative case from the NeedYD study. American Journal of Alzheimer's disease and other dementias. 2010;25:634-640.

30. Roach P, Keady J, Bee P, Hope K. Subjective experiences of younger people with dementia and their families: implications for UK research, policy and practice. Reviews in Clinical Gerontology 2008;18:165-174.

31. Bentham P, La Fontaine J. Services for younger people with dementia. Psychiatry 2008;7:84-87. 
32. Tindall L, Manthorpe J. Early onset dementia: A case of ill-timing? Journal of Mental Health 1997;6:237-250.

33. Baker B. When Alzheimer's Strikes. Workforce Management 2008;87:24-26.

34. DEEP. Tips for employers who want to be more dementia friendly. DEEP: The Dementia Engagement and Empowerment Project [internet]. 2013 Available from: http://dementiavoices.org.uk/wp-content/uploads/2013/11/DEEP-Guide-Tips-foremployers.pdf.

36. Dibia V, Trewin S, Ashoori M, Erickson T. Exploring the potential of wearables to support employment for people with mild cognitive impairment. In Proceedings of the 17th International ACM SIGACCESS Conference on Computers \& Accessibility, 401-402;2015.

35. Roach P, Drummond N. 'It's nice to have something to do': early-onset dementia and maintaining purposeful activity. Journal of Psychiatric and Mental Health Nursing 2014;21(10):889-895.

37. Alzheimer's Society. Employment. Living With Dementia [internet]. 2016. Available from: https://www.alzheimers.org.uk/download/downloads/id/1016/living_with_dementia__employment.pdf\%E2\%80\%9D -

38. Alzheimer's Organization. Younger-onset Alzheimers. [internet]. 2011. Available from: https://www.alz.org/library/downloads/youngeronset rl2011.pdf

39. Alzheimer's Australia. Employment and younger onset dementia [internet].. 2014. Available from: https://fightdementia.org.au/support-and-services/i-have-dementia/i-have-younger-onsetdementia/employment-and-younger-onset-dementia.

40. Alzheimer's Society. Employment [internet]. London: Alzheimer's Society. 2010.

41. Anonymous. Are You Ready to Act as More Employees Develop Early Onset Alzheimer's? IOMA's Safety Director's Report 2004;4:1-15.

42. Young Dementia UK. Working \& volunteering [internet]. 2014. Available from:. http://www.youngdementiauk.org/working-volunteering. 2014.

43. Batsch NL, Miller RV. An Assessment of Needs for Serving Individuals Diagnosed With Alzheimer's Disease and Related Dementias in the Early Stages. Alzheimer's Care Today. 2009;10;140-155.

44. Chaston D. Between a rock and a hard place: Exploring the service needs of younger people with dementia. Contemporary Nurse 2011;39;130-139.

45. Royal College Of Psychiatrists And Alzheimer's Society. Services for younger people with Alzheimer's disease and other dementias. London: Royal College of Psychiatrists. 2006.

46. ONS. Projections of the UK Labour Force, 2006 to 2020. 2006.

47. Taylor P. Employment and Labour Market Policies for an Ageing Workforce and Initiatives at the Workplace. National overview report: United Kingdom. 2007. London: European Foundation for the Improvement of Living and Working Conditions. 
48. Corrada MM, Brookmeyer R, Paganini- Hill A, Berlau D, Kawas CH. Dementia incidence continues to increase with age in the oldest old: the 90+ study. Annals of Neurology. 2010 Jan $1 ; 67(1): 114-21$.

604

605

606 
608

\begin{tabular}{|c|c|c|c|c|c|c|}
\hline \multirow{2}{*}{ Type of Article } & \multicolumn{5}{|c|}{ Country of Publication } & \multirow{2}{*}{ Total } \\
\hline & UK & USA & \begin{tabular}{|l|} 
Austalia/ \\
New \\
Zealand
\end{tabular} & Other & Joint & \\
\hline Journal article & 10 & 5 & 3 & 3 & 1 & 22 \\
\hline Professional/magazine article & 4 & 2 & 0 & 0 & 0 & 6 \\
\hline Brochure/Guidance & 4 & 1 & 0 & 0 & 0 & 5 \\
\hline Policy report/statement & 4 & 2 & 0 & 0 & 0 & 6 \\
\hline Webpage & 0 & 0 & 2 & 0 & 0 & 2 \\
\hline Press release & 2 & 0 & 0 & 0 & 0 & 2 \\
\hline \multirow[t]{2}{*}{ Thesis } & 1 & 0 & 0 & 0 & 0 & 1 \\
\hline & 26 & 10 & 5 & 3 & 1 & 44 \\
\hline
\end{tabular}

609

610

611 
612 Table 2. Critical Appraisals Skills Programme Qualitative Research Checklist Scores for Journal

613 Articles

614

\begin{tabular}{|l|l|l|}
\hline Author & Year & Score \\
\hline Harris \& Keady & 2009 & 10 \\
\hline Mitchell & 2012 & 10 \\
\hline Pipon-Young et al. & 2011 & 10 \\
\hline Batsch \& Miller & 2009 & 9 \\
\hline Chaplin and Davidson & 2016 & 9 \\
\hline Clemerson et al. & 2014 & 9 \\
\hline Roach \& Drummond & 2014 & 9 \\
\hline Van Vliet et al. & 2011 & 9 \\
\hline Bakker et al. & 2010 & 8 \\
\hline Haase & 2005 & 8 \\
\hline Roach et al & 2008 & 8 \\
\hline Wahab \& Ikebucu & 2014 & 8 \\
\hline Chaston & 2011 & 7 \\
\hline Keady \& Nolan & 1994 & 6 \\
\hline Thompson & 2011 & 5 \\
\hline Werner et al. & 2009 & 5 \\
\hline Dibia et al. & 2015 & 4 \\
\hline Tindall \& Manthorpe & 1997 & 2 \\
\hline Chaston & 2010 & 0 \\
\hline Baker & 2008 & N/A \\
\hline Bentham \& La Fontaine & 2008 & N/A \\
\hline Dodson & 1985 & N/A \\
\hline & &
\end{tabular}

615

616

617 


\begin{tabular}{|l|l|}
\hline Themes & Sub-themes \\
\hline Early presentation and identification in the workplace & $\begin{array}{l}\text { Hiding difficulties } \\
\text { Early symptoms } \\
\text { From symptoms to diagnosis } \\
\text { Interactions with employees }\end{array}$ \\
\hline Reasonable adjustments & $\begin{array}{l}\text { The desire to stay in work } \\
\text { Typical adjustments } \\
\text { Process of making adjustments } \\
\text { Reported experiences of reasonable adjustments }\end{array}$ \\
\hline Provision of information & $\begin{array}{l}\text { Raising awareness } \\
\text { Facilitating informed choice }\end{array}$ \\
\hline
\end{tabular}




\begin{tabular}{|c|c|c|c|}
\hline REASONABLE ADJUSTMENTS & $\begin{array}{l}\text { Alzheimer's } \\
\text { Society (2010; } \\
2016)\end{array}$ & $\begin{array}{l}\text { Job Access } \\
\text { website }\end{array}$ & $\begin{array}{l}\text { Alzheimer's } \\
\text { Australia }\end{array}$ \\
\hline changing work schedules, or reducing hours & $\mathrm{XX}$ & $\mathrm{X}$ & \\
\hline $\begin{array}{l}\text { arranging meetings for times when employees are } \\
\text { likely to be at their best }\end{array}$ & $\mathrm{x}$ & & \\
\hline $\begin{array}{l}\text { simplifying routines, and allocating tasks separately } \\
\text { instead of all at once }\end{array}$ & $x$ & & \\
\hline reducing noise and distraction & $\mathrm{x}$ & & \\
\hline $\begin{array}{l}\text { using technology (e.g. computerised diaries) to } \\
\text { function as reminders of meetings and deadlines }\end{array}$ & $\mathrm{X}$ & & \\
\hline $\begin{array}{l}\text { moving to a less senior role and accepting a lower } \\
\text { wage and less responsibility }\end{array}$ & $x$ & & \\
\hline having one or two colleagues as supporters & & $\mathrm{x}$ & $\mathrm{X}$ \\
\hline $\begin{array}{l}\text { assistance with planning for the future e.g. deciding } \\
\text { when the time is right to leave work }\end{array}$ & & $\mathrm{x}$ & \\
\hline $\begin{array}{l}\text { identify who else in the workplace needs to know } \\
\text { about the diagnosis. (clients as well as co-workers) }\end{array}$ & & & $x$ \\
\hline
\end{tabular}

623

624

625

626 
Table 5. Good practice in the process of making adjustments at work

\begin{tabular}{|l|c|c|}
\hline GOOD PRACTICE FOR EMPLOYERS & $\begin{array}{l}\text { Alzheimer's } \\
\text { Society } \\
(2014)\end{array}$ & $\begin{array}{c}\text { DEEP } \\
(2013)\end{array}$ \\
\hline $\begin{array}{l}\text { Encourage an open and honest dialogue of options to help the person stay in } \\
\text { work }\end{array}$ & $\mathrm{X}$ & $\mathrm{X}$ \\
\hline $\begin{array}{l}\text { Seek further advice to identify ways to make reasonable adjustment, e.g. OH } \\
\text { services, local memory services }\end{array}$ & $\mathrm{x}$ \\
\hline $\begin{array}{l}\text { Demonstrate they have made reasonable adjustments to enable people who } \\
\text { develop dementia to continue to work, and reassure employees that the } \\
\text { organisation will support them where possible }\end{array}$ & $\mathrm{x}$ \\
\hline $\begin{array}{l}\text { Be flexible and use the skills of the individuals involved, adjusting certain } \\
\text { parts of the job where necessary }\end{array}$ & & $\mathrm{x}$ \\
\hline \begin{tabular}{l} 
Make sure the person knows that their skills and experience are still valued \\
\hline $\begin{array}{l}\text { Carry out risk assessments and review the situation frequently with the } \\
\text { employee }\end{array}$
\end{tabular} & $\mathrm{x}$ \\
\hline $\begin{array}{l}\text { Acknowledge that supporting people may take time and resources - people } \\
\text { may need practical and emotional support }\end{array}$ & $\mathrm{x}$ \\
\hline $\begin{array}{l}\text { Be honest about adjustments that can reasonably be made, and provide } \\
\text { information and guidance about finishing work to people with dementia and } \\
\text { carers who are unable, or no longer wish to, continue working }\end{array}$ & $\mathrm{x}$ & $\mathrm{x}$ \\
\hline
\end{tabular}


Figure 1. Flow chart for the identification of articles

632

633

634

635

636

637

638

639

640

641

642

643

644

645

646

647

648

649

650

651 